\title{
Laparoscopic excision of infected mesh
}

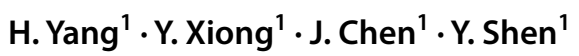

Received: 21 July 2019 / Accepted: 7 August 2019 / Published online: 24 August 2019

c) Springer-Verlag France SAS, part of Springer Nature 2019

\section{Dear Editor}

After reading the comment from Gachabayov $\mathrm{M}$ on our published study [1, 2], I do not think that our laparoscopic method of mesh removal was understood clearly. Therefore, I would like to explain this in detail, and this method has been addressed clearly in our previously published paper [3].The first step was to explore the abdominal cavity thoroughly and to identify the infection. After the abscess of the abdominal wall was identified, a small incision was made at its lateral margin using endoscopic scissors. The pus from the abscess was aspirated completely to avoid contamination of the abdominal cavity and a pus sample was sent for culturing. Then, the peritoneum was developed approximately $2 \mathrm{~cm}$ above the internal inguinal ring to explore the infected mesh. The mesh was divided away with the laparoscopic grasper and suction. Separation of the mesh, especially from the pubic bone, can be difficult, and great care was taken to avoid injury to the bladder, inferior epigastric vessels, or iliac vessels. After thorough irrigation of the preperitoneal pocket, a drain with flushing function was inserted. The peritoneal flap was closed with $3 / 0$ absorbable consecutive suture. If an abdominal wall sinus was present, an additional open excision was performed after methylene blue injection through the sinus. I hope the above explanation made it clear.
Authors' contribution YH wrote the manuscript. XY collected the data for this study. SY and CJ supervised the study.

\section{Compliance with ethical standards}

Conflict of interest The authors declare that they have no confict of interest.

Ethical approval This study complied the current law of China.

Human and animal rights All procedures performed in studies involving human participants were in accordance with the ethical standards of the institutional and with the 1964 Helsinki declaration and its later amendments or comparable ethical standards.

Informed consent Inform consent was obtained from all individual participants included in this study.

\section{Reference}

1. Yang H, Xiong Y, Chen J, Shen Y (2019) Study of mesh infection management following inguinal hernioplasty with an analysis of risk factors: a 10-year experience. Hernia. https://doi.org/10.1007/ s10029-019-01986-w

2. Gachabayov M, Gogna S, Latifi R (2019) En bloc removal of infected hernia mesh rather than "blue-ectomy". Hernia. https:// doi.org/10.1007/s10029-019-02012-9

3. Yang H, Liu Y, Chen J, Shen Y (2019) The management of mesh infection after laparoscopic inguinal hernia repair. Surg Laparosc Endosc Percutan Tech 29:40-42

Publisher's Note Springer Nature remains neutral with regard to jurisdictional claims in published maps and institutional affiliations.

This reply refers to the comment available at https://doi. org/10.1007/s 10029-019-02012-9

\section{J. Chen}

chenjiejoe@sina.com

1 Department of Hernia and Abdominal Wall Surgery, The Capital Medical University Beijing Chaoyang Hospital, Jingyuan Road No.5, Shijingshan District, Beijing 100043, China 